Dhaka Univ. J. Sci. 60(1): 25-29, 2012 (January)

\title{
Investigations on Microstructural and Layer Disorder Parameters of Na-Montmorillonite- Glycine Intercalation Compounds
}

\author{
Adnan Hossain Khan ${ }^{1}$, Parimal Bala ${ }^{2}$, A. F. M. Mustafizur Rahman ${ }^{1}$, and Mohammad Nurnabi ${ }^{*}$ \\ ${ }^{1}$ Department of Applied Chemistry and Chemical Engineering, University of Dhaka, Dhaka-1000, Bangladesh \\ ${ }^{2}$ Department of Physics, Jagannath University, Dhaka-1100, Bangladesh
}

Received on 12.08.2010. Accepted for Publication on 20.08.2011

\begin{abstract}
Glycine-Montmorillonite (Gly-MMT) composite has been synthesized through intercalation process using Na-Montmorillonite (NaMMT) and glycine ethylester hydrochloride. Gly-MMT was employed for the synthesis of dipeptide (Gly-Gly-MMT). Microstructural parameters such as crystallite size, r.m.s. strain $\left(\left\langle\mathrm{e}^{2}\right\rangle^{1 / 2}\right)$ and layer disorder parameters such as variation of interlayer spacing $(\mathrm{g})$ and proportion of planes affected by such defects $(\gamma)$ of the samples have been calculated by X-ray line profile analysis. In comparison to Na-MMT the basal spacings $\left(\mathrm{d}_{001}\right)$ of Gly-MMT and Gly-Gly-MMT were reduced by $2.4 \AA$ and $1.8 \AA$ respectively. The value of $\mathrm{d}_{001}$ of Gly-Gly-MMT (13.3 $\AA$ ) suggests the monolayer orientation of dipeptide into interlayer spaces. It is also suggested that more homogeneity in the stacking of silicate layers is attained in Gly-Gly-MMT due to the increased chain length of the dipeptide and orientation in monolayer style.
\end{abstract}

Key words : Glycine ethylester, montmorillonite, intercalation, crystallite, isomorphous, nanocomposites, microstructural.

\section{Introduction}

Montmorillonite is a 2:1 type of layer structure clay mineral consisting of negatively charged silica sheets separated by a van der Waals interlayer gallery containing chargebalancing counterions such as $\mathrm{Mg}^{2+}, \mathrm{Na}^{+}$and $\mathrm{Ca}^{2+}$ etc. These interlayer cations balance the negative charges, which are generated by the isomorphous substitution of $\mathrm{Mg}^{2+}$ and $\mathrm{Fe}^{2+}$ for $\mathrm{Al}^{3+}$ in the octahedral sheet and $\mathrm{Al}^{3+}$ for $\mathrm{Si}^{4+}$ in tetrahedral sheet. The interesting feature of montmorillonite structure is that the interlayer cations can be replaced easily by either organic or inorganic molecules through a process called intercalation, which allows a convenient method for making new composites suitable for different applications such as catalysts ${ }^{1}, \operatorname{cosmetics}^{2}$, nuclear waste treatment ${ }^{3}$, etc. Moreover, by exploiting this intercalation behavior, montmorillonite is being used in preparation of different types of polymeric-clay nanocomposites and hybrid materials with better physical, mechanical and thermal properties $^{4-7}$. It is important to note that the preparation of clay based materials and their suitability in different applications are predominantly governed by their physicochemical properties such as strength, plasticity, compressibility, swelling etc which are largely depended on the microstructure and the disorder anisotropy present in layer stacking. Thus the intercalation of different organic molecules into montmorillonite interlayers and investigation of various microstructural properties are of great importance to the users of these compounds ${ }^{8-10}$. Due to the interesting structural features of layer structured clay minerals X-ray diffraction pattern played an important role for their characterization and especially basal (001) reflection is preferred $^{11-14}$. However, this basal reflection is highly sensitive to interlayer distances, intralayer charge, interlayer cations density, and water molecules, which are present between the layers. Since the interlayer cations and intralayer charge density in not homogeneous from layer to layer ${ }^{14,15}$, a variation in the stacking of layers along cdirection is highly expected, which will affect $00 l$ reflections, especially 001 by a greater factor. Thus the parameters, which can characterize these variations, may be important for better understanding of the different properties of pure and organomodified clay minerals. So this type of characterization of clays and organomodified clays has drawn the attention of many researchers ${ }^{9,16-20}$. Polymer clay nanocomposites have been produced with an extensive array of synthetic polymers having potential applications, such as biopolymers incorporated clays found applications in drug delivery, biomedical engineering and pharmaceuticals ${ }^{21}$. Studies on biopolymer-clay composites such as Lysine$\mathrm{MMT}^{22}$, lysine-, arginine- and histidine-MMT ${ }^{23}$, Poly $(\mathrm{L}-$ lysine)/Na-Montmorillonite ${ }^{24}$ have been reported. To the best of our knowledge incorporation of glycine $\alpha$-amino acid, which is a building block in the biological systems into montmorillonite interlayers and hence synthesis of dipeptide and their microstructural and layer disorder parameters characterization has not been investigated so far. Thus in the present investigation, glycine ethylester has been intercalated into Na-montmorillonites interlayers, which further reacted with a second unit of glycine ethylester to afford a clay bound Gly-Gly dipeptide. The microstructural parameters like crystallite size $\left(\mathrm{P}_{\mathrm{v}}, \mathrm{P}_{\mathrm{F}}\right)$, r.m.s. strain $\left(<\mathrm{e}^{2}>^{1 / 2}\right)$, and layer disorder parameters such as variation of interlayer spacing $(\mathrm{g})$ and proportions of planes affect by such defects $(\gamma)$ have been calculated from X-ray diffraction line profile analysis.

\section{Materials and Methods}

Na-montmorillonite (SWy-1, cation exchange capacity = $76.4 \mathrm{meq} / 100 \mathrm{~g}$, Clay Mineral Society, University of Missouri, Columbia) was used in the present work and intercalated using Glycine ethylester hydrochloride $\left(\mathrm{C}_{4} \mathrm{H}_{9} \mathrm{NO}_{2} \cdot \mathrm{HCl}\right)$. Considering the cation exchange capacity

*Corresponding author-nnabi@du.ac.bd 
and the structure of Na-MMT the intercalation was carried out following the method available in the literature ${ }^{9,24,25}$. Glycine-ethylester hydrochloride $(0.864 \mathrm{~g}, 6.0 \mathrm{mmol})$ was taken and mixed with concentrated $\mathrm{HCl}(1 \mathrm{~mL})$ and water $(30 \mathrm{~mL})$ in a round bottom flask and stirred vigorously at $80^{\circ} \mathrm{C}$ for 15 minutes. The mixture was then poured into $\mathrm{Na}-$ MMT dispersion $\left(2.5 \mathrm{~g}\right.$ in $\left.100 \mathrm{~mL} \mathrm{H}_{2} \mathrm{O}\right)$ and heated at $80^{\circ} \mathrm{C}$ with vigorous stirring for 45 minutes. The precipitate so formed was filtered and washed repeatedly with distilled water to make it free from the chloride ion. The product was subsequently dried in air atmosphere to afford colourless powder. The synthesized compound was termed as GlyMMT where Gly stands for glycine ethylester and MMT for montmorillonite. In case of the synthesis of Gly-Gly-MMT compound, $0.56 \mathrm{gm}$ of Gly-MMT was suspended in dry dichloromethane (DCM) $(10 \mathrm{~mL})$ and stirred for 15 minutes in a double neck round bottle flask. In another flask, glycine ethylester hydrochloride $(0.28 \mathrm{gm}, 2.0 \mathrm{mmol})$ was suspended in DCM $(5 \mathrm{~mL})$ and treated with triethylamine (2.2 mmol) and mixed well. The solution of glycine ethylester was added into the suspension of Gly-MMT in three equal steps $(3.0 \mathrm{~mL}$ each time) and stirred for 20 minutes after each addition. The product was then filtered, washed with DCM $(2 \times 10 \mathrm{~mL})$ and air dried to achieve powdered material.

The X-ray diffraction (XRD) intensities of the compounds were recorded with a Philips, X'Pert PRO XRD PW 3040, $\mathrm{X}$-ray diffractometer using monochromatic $\mathrm{CuK} \alpha$ $(\lambda=1.542 \AA)$ radiation. To study the microstructural parameters, the XRD intensities were corrected for background, geometrical and Lorentz polarization factors ${ }^{19,20,26}$. The value of $g$ and $\gamma$ for all the samples were calculated by adopting a single line technique and applying equations (eq.1-4) followed by Mitra and Bhattacherjee ${ }^{19}$, De and Bhattacherjee ${ }^{20}$, Mandal et. al. ${ }^{27}$, Bala et. al. ${ }^{16}$

$$
g=\frac{1}{\pi l} \cot ^{-1} \frac{\pi \Delta}{\beta_{d}},
$$

and $\gamma=\frac{\beta_{d}}{\sin ^{2}(\pi . l . g)} \ldots \ldots \ldots \ldots \ldots \ldots . .$.

where $\beta_{d}$ is the integral width of the defect profile, $\Delta$ the measure of peak shift from the centroid of the diffraction profile, and $l$ the order of reflection ${ }^{16,27}$. The values of apparent crystallite size $\left(\mathrm{P}_{\mathrm{V}}\right)$ and r.m.s. strain $\left.\left(<\mathrm{e}^{2}\right\rangle^{1 / 2}\right)$ were determined from X-ray diffraction (XRD) profiles using the equations

$$
\begin{aligned}
& W_{2 \theta}=\frac{\alpha \lambda}{2 \pi^{2} P_{V} \cos \theta}+\frac{S \lambda^{2}}{\cos ^{2} \theta} \\
& \text { and } \frac{1}{P_{V}}=\frac{1}{P_{F}}+\frac{\beta_{d}}{d},
\end{aligned}
$$

where $\quad \mathrm{S}=\left(<\mathrm{e}^{2}>-\beta_{\mathrm{d}}{ }^{2} / \pi^{2}\right) / \mathrm{d}^{2}$ where $W_{2 \theta}$ is the variance of the profile and $\alpha$ is the angular range over which the intensity distribution is appreciable, $\left\langle\mathrm{e}^{2}\right\rangle$ is the mean square strain, $\lambda$ is the wavelength of the $\mathrm{X}$ ray, $\theta$ is Bragg angle, $d$ is the interplanar spacing, and $P_{V}$ is the apparent crystallite size. Thus if the graphs of $\mathrm{W}_{2 \theta}$ against $\alpha$ are plotted, a straight-line graph should be obtained and from its slopes and intercepts $\mathrm{P}_{\mathrm{V}}$ and $\left\langle\mathrm{e}^{2}\right\rangle$ can be calculated ${ }^{16,27}$. The values of the true crystallite size $\left(\mathrm{P}_{\mathrm{F}}\right)$ have been evaluated following Warren and Averbach's method of Fourier analysis ${ }^{28}$.

\section{Results and Discussion}

Scheme 1 represents the possible reaction mechanism taking place in the synthesis of Gly-MMT and Gly-Gly-MMT. The formation of dipeptide into the interlayer galleries of montmorillonite has been justified by thermogravemetric analysis (TGA), differential thermal analysis (DTA) and Fourier transform infrared (FTIR) analysis of the samples presented elsewhere ${ }^{29}$. Figure 1 shows the X-ray diffraction profiles of Na-MMT, Gly-MMT, Gly-Gly-MMT for 001 reflection, which has been used to calculate $\mathrm{P}_{\mathrm{V}}, \mathrm{P}_{\mathrm{F}},\left\langle\mathrm{e}^{2}\right\rangle^{1 / 2}, \mathrm{~g}$ and $\gamma$. The values of $P_{V}$ and $\left\langle e^{2}\right\rangle^{1 / 2}$ were calculated from the intercept of the abscissa and the slope of the variance $\left(\mathrm{W}_{2 \theta}\right)$ - range $(\alpha)$ plots (Figure2) ${ }^{16,27}$. The linear relationship in the variance-range plot establishes the correctness of the background corrections. Different microstructural and layer disorder parameters for Na-MMT, Gly-MMT and Gly-GlyMMT are presented in Table 1.

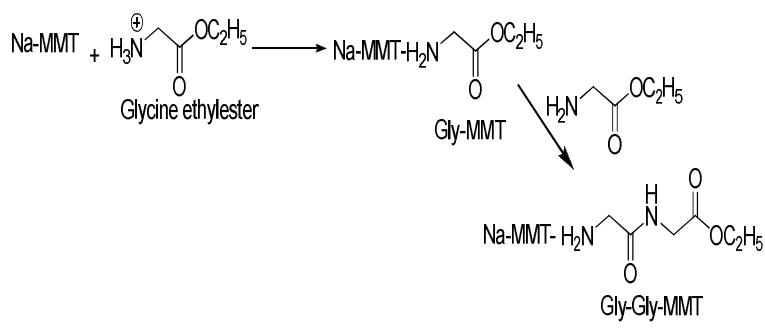

Scheme 1. Synthesis of Gly-MMT and Gly-Gly-MMT.

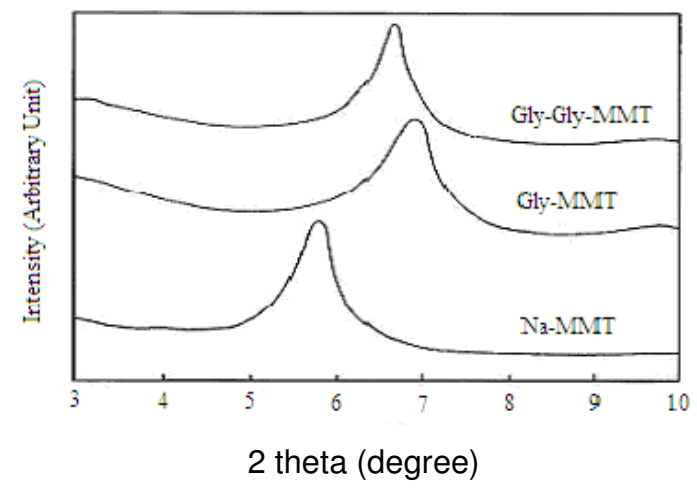

Fig. 1. X-ray diffraction profiles for the 001 reflection of NaMMT, Gly-MMT and Gly-Gly-MMT 


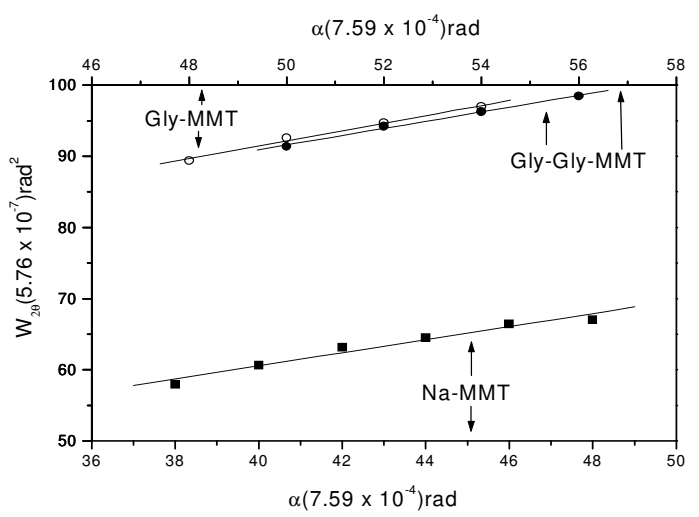

Fig.2. Variance $\left(\mathrm{W}_{2 \theta}\right)$ - range $(\alpha)$ plots for the 001 reflection of Na-MMT, Gly-MMT and Gly-Gly-MMT.
It is observed that the peak position corresponding to 001 reflection for Na-MMT with hydrated $\mathrm{Na}^{+}$is shifted towards higher angle region (2 $\theta$ ) resulting in a decrease in basal spacing, when it is intercalated by glycine ethylester (Gly). This decrease of basal spacing confirms the exchange of hydrated $\mathrm{Na}^{+}$by the Gly. This agreed well with ethylendiammonium $\left(\mathrm{EDAH}^{++}\right)$intercalation compound ${ }^{29}$ and alkylammonium intercalation compounds ${ }^{9}$. The basal spacing of montmorillonite intercalation compounds mainly depends on the chain length of intercalates and their orientation. The intercalates may be arranged in different ways like monolayer, bilayer and paraffin types. The basal spacing for alkylammonium-MMT compounds are $\approx 13.6 \AA$ (for monolayer) and $\approx 17.7 \AA$ (for bilayer) respectively ${ }^{30-33}$. In the present investigation the basal spacing of Gly-MMT and Gly-Gly-MMT were found to be $12.7 \AA$ and $13.3 \AA$ respectively, wherein it was $15.1 \AA$ for Na-MMT. The basal

Table. 1. Microstructural and layer disorder parameters of Na-MMT, Gly-MMT and Gly-Gly-MMT

\begin{tabular}{lccc}
\hline Parameters & Na-MMT & Gly-MMT & Gly-Gly-MMT \\
\hline Interplaner spacing, $\mathrm{d}_{001}(\AA)$ & 15.12 & 12.72 & 13.27 \\
Crystallite size, $\mathrm{P}_{\mathrm{V}}(\AA)$ & 108 & 83 & 89 \\
Crystallite size, $\mathrm{P}_{\mathrm{F}}(\AA)$ & 127 & 102 & 110 \\
Variation in interlayer spacing, $\mathrm{g}$ & 0.442 & 0.447 & 0.417 \\
Proportion of planes affected, $\gamma$ & 0.081 & 0.088 & 0.058 \\
r.m.s. strain, $<\mathrm{e}^{2}>^{1 / 2} \times 10^{2}$ & 4.7 & 3.5 & 3.8 \\
\hline
\end{tabular}

spacing found in Gly-Gly-MMT is very close to that of monolayer compounds but the basal spacing found in GlyMMT compound is nearly $0.6 \AA$ less than that of Gly-Gly compound which may be due to the occupation of the Gly in the hexagonal holes present in the tetrahedral sheets or to kinks to the monolayer chains. The similar type of results also observed when montmorillonite is intercalated with methyl ammonium ${ }^{9}$. Interestingly, the increase of basal spacing in Gly-Gly-MMT compared to Gly-MMT justified that further addition of glycine ethylester to Gly-MMT produced dipeptide which increased length of the intercalate and it was large enough not to occupy the hexagonal holes.

The values of the crystallite size obtained in the present investigation are $108 \AA, 83 \AA$ and $89 \AA$ for Na-MMT, GlyMMT and Gly-Gly-MMT respectively (Table 1.). It was observed that crystallite size decreased for Gly-MMT than that for pure Na-MMT. However, the crystallite size of GlyGly-MMT was slightly bigger than that of Gly-MMT. The lower value of crystallite size in case of Gly-MMT with respect to Na-MMT can be attributed to the fact that Gly is being intercalated in the interlayer spaces of Na-MMT by substituting hydrated $\mathrm{Na}^{+}$ions. The similar type of result is also observed when hydrated $\mathrm{Na}^{+}$ions are substituted with methyl ammonium from montmorillonite interlayers ${ }^{9}$. It has been reported that when longer chain alkylammonium is intercalated, the crystallite size increases than that for the intercalated compound having shorter chain length ${ }^{9}$. In the present investigation, it appears that the little increase of crystallite size in the case of Gly-Gly-MMT with respect to Gly-MMT is due to the formation of dipeptide of Gly which increases chain length of the intercalates. It is further observed that Na-MMT is associated relatively with greater $\left\langle\mathrm{e}^{2}\right\rangle^{1 / 2}$ values and is possibly related to the layer charge, interlayer cations distribution and the water molecules being present in the interlayer space. The relative decrease in $\left\langle\mathrm{e}^{2}\right\rangle^{1 / 2}$ in Gly-Gly-MMT and Gly-MMT is more likely to be due to the lesser amount of adsorbed water in the interlayer space $^{16}$. It was observed that the variability change in interlayer spacing $(\mathrm{g})$ and fractions of the planes affected by such variations $(\gamma)$ were lower for Gly-Gly-MMT and little higher for Gly-MMT than that for pure Na-MMT. It seems that the distribution, chain length and orientation of interlayer organic species are responsible for the observed variation in the value of $g$ and $\gamma^{13,14}$. In the present investigation the variation in the value of $g$ can be attributed to the fact that intercalates are oriented in a random way in Gly-MMT with the possibility of occupation in the hexagonal holes present in montmorillonite layers which may happens due to its shorter chain length and possibly be responsible for higher value compared to that for Gly-GlyMMT where the chain length of the intercalates increased and oriented in monolayer style. The values of $g$ obtained 
for Gly-Gly-MMT also indicated that stacking of silicate sheets are more homogeneous here than in pure Na-MMT and Gly-MMT and the value of $\gamma$ suggests that orientational asymmetry decreases in this compound.

\section{Conclusion}

Gly-MMT shows relatively lower value in crystallite in comparison to that of pure Na-MMT but Gly-Gly-MMT shows little increase in crystallite size confirming the formation of dipeptide. More homogeneity in the stacking of silicate layers is achieved in Gly-Gly-MMT compound. The lower values in r.m.s strain of Gly-MMT and Gly-GlyMMT may be correlated to the organophilic nature of the compound.

\section{Acknowledgement}

Authors are very thankful to Professor B K Samantaray, Department of Physics and Meteorology, Indian Institute of Technology, Kharagpur, India for his kind guidance in calculation of the microstructural and layer disorder parameters.

1. Chen, M., L Fan, L. Qi, X. Luo, R. Zhou, X. Zheng, 2009. The catalytic combustion of VOCs over copper catalysts supported on cerium-modified and zirconium-pillared montmorillonite. Catal. Commun. 10, 838-841.

2. Lopez-Galindo, A., C. Viseras and P. Cerezo, 2007. Compositional, technical and safety specifications of clays to be used as pharmaceutical and cosmetic products. Appl. Clay Sci. 36, 51-63.

3. Sazarashi, M., Y. Ikeda, R. Seki and H. Yoshikawa, 1994. Adsorption of Ions on minerals for ${ }^{129} \mathrm{I}$ waste management. J. Nucl. Sci. Tech. 31, 620-622.

4. Anadao P., L. F. Sato, H. Wiebeck and F. R. Valenzuela-Díaz, 2010. Montmorillonite as a component of polysulfone nanocomposite membranes. Appl. Clay Sci. 48, 127-132.

5. Li, P., G. Song, L. Yin, L. Wang and G. Ma, 2008. New toughened poly-propylene/organophilic montmorillonite nanocomposites. J. Appl. Polym. Sci. 108, 2116-21.

6. Sun, Y., Y. Luo and D. Jia, 2008. Preparation and properties of natural rubber nanocomposites with solid-state organomodified montmorillonite. J. Appl. Polym. Sci. 107, 2786-92.

7. Bala, P., B. K. Samantaray, S. K. Srivastava and G. B. Nando, 2004. Organomodified montmorillonite as filler in natural and synthetic rubber. J. Appl. Polym. Sci. 92, 3583-92.

8. Akelah, A., A. Moet, 1996. Polymer-clay nanocomposites: Free radical grafting of polystyrene on to organophilic montmorillonite interlayers. J. Matter. Sci. 31, 3589-

9. Bala, P., B. K. Samantaray and S. K. Srivastava, 2000. Synthesis and characterization of Na-montmorillonitealkylammonum intercalation compounds. Mater. Res. Bull. 35, 1717-24.
10. Yoon, K., H. Sung, H. Hwang, S. K. Noh and D. Lee, 2007. Modification of montmorillonite with oligomeric amine derivatives for polymer nanocomposite preparation Appl. Clay Sci. 38, 1-8

11. He, H., Y. Ma, J. Zhu, P. Yuan and Y. Qing, 2010. Organoclays prepared from montmorillonites with different cation exchange capacity and surfactant configuration. Appl. Clay Sci. 48, 67-72.

12. Kornmann, X., L. A. Berglund, J. Sterte, E. P. Giannelis, 1998. Nanocomposites based on montmorillonite and unsaturated polyester Polym. Engin. Sci. 38, 1351-1358.

13. Akelah, A., P. Kelly, S. Qutubuddin and A. Moet, 1994. Synthesis and characterization of 'epoxyphilic' montmorillonites. Clay Miner. 29, 169-178.

14. Lagaly, G., 1981. Characterization of clays by organic compounds. Clay Miner. 16, 1- 21.

15. MacEwan, D. M. C., M. J. Wilson, 1980. Crystal Structure of Clay Minerals and their X-ray Identification (Eds G. W. Brindley and G. Brown) Mineralogical Society, London. pp. $197-248$.

16. Bala, P., B. K. Samantaray, S. K. Srivastava and H. Haeuseler, 2000. Microstructural parameters and layer disorder accompanying dehydration transformation in $\mathrm{Na}$ montmorillonite. Z. Kristallogr. 215, 235-9.

17. Bala, P., B. K. Samantaray and S. K. Srivastava, 2000. Investigations on variation of interlayer spacing and other microstructural parameters in dehydration transformation of vermiculite. Indian J. Phys. 74A, 1-5.

18. Bala, P. and B. K. Samantaray, 2000. Structural transformation accompanying dehydration of montmorillonite. Indian J. Phys. 74A, 99 - 102.

19. Mitra, G. B. and S. Bhattacherjee, 1969. X-ray diffraction studies on the transformation of kaolinite into metakaolin, I. Variability of interlayer spacings. Am. Miner. 54, 1409-1418.

20. De, A. K. and S. Bhattacherjee, 1985. An X-ray analysis of stacking disorder in kaolinite by fourth moment. Clay Miner. 20, 249-253.

21. Wu, C. J., A. K. Gaharwar, P. J. Schexnailder and G Gudrun, 2010. Development of Biomedical Polymer-Silicate Nanocomposites: A Materials Science Perspective. Materials 3, 2986-3005.

22. Davis, A. M., G. Joanis and L. Tribe, 2008. Molecular modeling of polymer-clay nanocomposite precursors: Lysine in montmorillonite interlayers. J. Computa. Chem. 29, 983987.

23. Hideo, H., 2002. Basal spacing of montmorillonite/amino acid complexes at different relative humidity. Clay Sci. 11, 565574.

24. Krikorian, V., M. Kurian, M. E. Galvan, A. P. Nowak and T. J. Deming, 2002. Polypeptide-Based Nanocomposite: Structure and Properties of Poly(L-lysine)/Na_Montmorillonite. J. Polym. Sci.: Part B: 40, 2579-2586.

25. Usuki, A., Y. Kojima, M. Kawasumi, A. Okada, T. Kurauchi and O. Kamigaito, 1993. Synthesis of Nylon 6-clay hybrid. J. Mater. Res. 8, 1174-1179. 
26. Stanjek, H., E. A. Niederbudde and W. Hausler, 1992. Improved evaluation of layer charge of n-alkylammonium treated fine soil clays by lorentz- and polarizations-corrections and curve-fitting. Clay Miner. 27, 3-19.

27. Mandal, T. K., S. K. Srivastava and B. K. Samantaray, 1997. Some studies on microstructural parameters, surface morphology and other properties of tungsten substituted molybdenum disulphide. Synth. Metal 90, 135-142.

28. Warren, B. E. and B. L. Averbach, 1950. The effect of coldwork distortion on X-ray pattern. J. Appl. Phys. 21, 595-602.

29. Khan, A. H., M. Nurnabi and P. Bala, 2009. Studies on thermal transformation of Na-montmorillonite-glycine intercalation compounds. J. Therm. Anal. Cal. 96, 929-935.

30. Laura, R. D., and P. Cloos, 1975. Adsorption of ethylenediamine (EDA) on montmorllonite saturated with different cations; III. Na-, K-, and Li-montmorillonite; ionexchange, protonation, co-ordination and hydrogen bonding. Clays Clay Miner. 23, 61-9.
31. Jordan, J. W., 1949. Organophilic bentonites, I. Swelling in organic liquid. J. Phys. Colloid. Chem. 53, 294-306.

32. Brindley, G. W. and R. W. Hoffmann, 1962. Orientation and packing of aliphatic chain molecules on montmorillonite. Clays Clay Miner. 9, 546-56.

33. Lagaly, G. and A. Weiss, 1971. Arrangement and orientation of cationic surfactants on silicate surfaces. IV. Arrangement of n-alkylammonium ions on weakly charged layer silicates. Kolloid. Z. Z. Polymer 243, 48-55. 